\title{
Cardiothoracic surgical education research is NOT for dabblers anymore
}

\author{
J. Alexander Weston, MD, and Elizabeth A. David, MD, MAS
}

\footnotetext{
From the Division of Thoracic Surgery, Department of Surgery, Keck School of Medicine, University of Southern California, Los Angeles, Calif.

Disclosures: Authors have nothing to disclose with regard to commercial support.

Received for publication Oct 23, 2018; accepted for publication Oct 23, 2018; available ahead of print Nov 30 , 2018.

Address for reprints: Elizabeth A. David, MD, MAS, 1510 San Pablo St, HCC 1 Suite 514, Los Angeles, CA 90033-4612 (E-mail: Elizabeth.David@med.usc.edu).

J Thorac Cardiovasc Surg 2019;157:829

$0022-5223 / \$ 36.00$

Copyright (c) 2018 by The American Association for Thoracic Surgery

https://doi.org/10.1016/j.jtcvs.2018.10.111
}

It is widely known that education is an undervalued profession, despite its importance in society. In the world of cardiothoracic surgical research, educational research has been considered a less meaningful contribution to science than attempts to cure aortic stenosis and lung cancer. As a result, cardiothoracic surgical education research (CSER) has suffered a dearth of quality and rigor. Many CSER investigators have been guilty of "dabbling" in CSER by doing a "simple" simulation study or a survey that lacks the same rigorous scientific methodologies as scientific literature asking clinical questions. In this issue of the Journal, Dr Antonoff and colleagues ${ }^{1}$ offer potential CSER investigators a snapshot into common methodologic pitfalls that frequently plague CSER articles during the peer-review process and opportunities to improve the scientific rigor of CSER.

Scientific rigor is used to improve clinical outcomes leading to better patient care, so why can it not be used to improve CSER and surgical education? This question is one of the central themes of the article, "Conducting High-Quality Research in Cardiothoracic Surgical Education: Recommendations From the Thoracic Education Cooperative Group." ${ }^{1}$ The authors have set out to describe a formalized step-by-step approach to designing an educational study that can be used to improve the training of our residents.

Antonoff and colleagues ${ }^{1}$ emphasize the importance of a valid scientific question for CSER. Much like basic science and clinical research, the question for CSER must be relevant, focused, and testable. The authors encourage the use of a literature search to guide the generation of a valid question. Next, the importance of choosing a rigorous and appropriate methodology to answer the research question is stressed. In addition, they encourage the use expert collaborators to assist with design and analysis of data, just as would be used for large-scale multicenter trials. entific studies.

\section{References} 332-54.

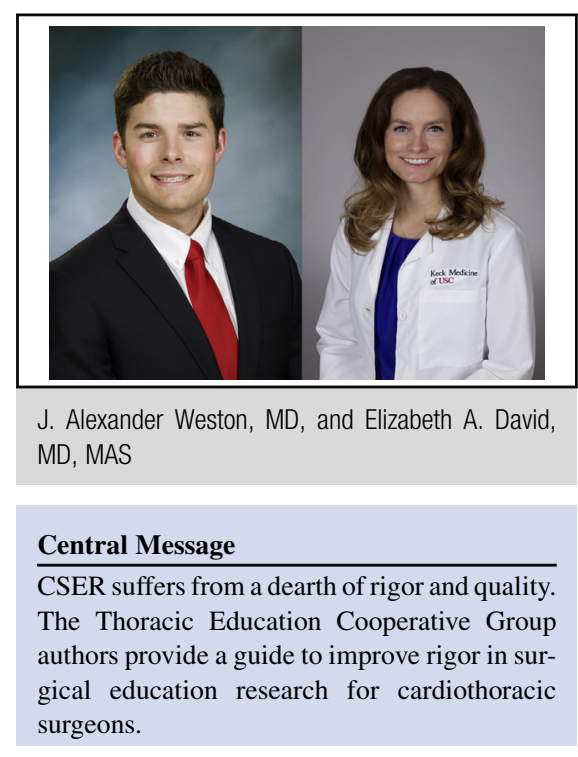

See Article page 820 .

Antonoff and colleagues ${ }^{1}$ also attempt to change the mindset that educational research should only be destined for editorials to educational research can be deeply rooted in scientific principles and appear in peer-reviewed journals with high impact factors. Antonoff and colleagues ${ }^{1}$ have done a brilliant job arguing for scientific rigor and detailing how to achieve this in CSER. Nonetheless, under the leadership of the Thoracic Education Cooperative Group, we should see the niche of surgical education blossom with sci-

For those interested in CSER, this article will serve you well as a guide on where to start and to see your project through to completion. With the advent of the Accreditation Council for Graduate Medical Education milestones, we have enhanced the rigor of our training programs, and in today's era of evidence-based medicine it is time to hold the same standards for our educational research. ${ }^{2}$ Let us make Dr William S. Halsted proud by bringing scientific rigor to educational research. CSER dabblers be aware, rigor is required for publication in 2018 and beyond!

1. Antonoff MB, Nguyen S, Nguyen TC, Odell DD. Conducting high-quality research in cardiothoracic surgical education: recommendations from the Thoracic Education Cooperative Group. J Thorac Cardiovasc Surg. 2019;157:820-7.

2. The thoracic surgery milestone project. J Grad Med Educ. 2014;6(1 Suppl 1): 